\title{
La legislación europea sobre contenidos audiovisuales: de la Directiva Televisión sin fronteras a los medios sociales ${ }^{1}$ \\ European legislation on audiovisual content: from the Television without
} Frontiers Directive to social media

Sagrario Beceiro

Universidad Carlos III (UC3M)

mbeceiro@hum.uc3m.es

Ana Mejón

Universidad Carlos III (UC3M)

amejon@hum.uc3m.es

Forma de citar este artículo:

Beceiro, S. y Mejón, A. (2019). “La legislación europea sobre contenidos audiovisuales: de la Directiva Televisión sin fronteras a los medios sociales", RAEIC, Revista de la Asociación Española de Investigación de la Comunicación, vol 5, núm. 11, 24-45.

DOI: https://doi.org/10.24137/raeic.6.11.3

\section{Resumen:}

Desde la publicación, en el año 1989, de la primera Directiva Televisión sin fronteras (TSF) en Europa, la legislación sobre contenidos audiovisuales (programas y servicios) en el ámbito de la Unión Europea (UE) ha estado marcada por emergentes directrices políticas (liberalismo, desregulación y re-regulación) y avatares de la evolución del

\footnotetext{
${ }^{1}$ Este trabajo es una actualización de la ponencia BECEIRO, S. (2012) “Evolución de la legislación audiovisual en la Unión Europea en el entorno digital: los contenidos se independizan del soporte", Congreso AE-IC, Comunicació i risc: III Congrés Internacional Associació Espanyola d'Investigació de la Comunicació. La nueva investigación se desarrolla en el marco del proyecto I+D+i “Cine y televisión en España 1986-1995: modernidad y emergencia de la cultura global" Ref. CSO2016-78354-P.
}

RAEIC, Revista de la Asociación Española de Investigación de la Comunicación vol. 6, núm. 11 (2019), 24-45 
mercado. En la búsqueda del equilibrio legislativo, aspirando a no quedar rezagada ni adelantarse respecto a los acontecimientos del sector, la Directiva TSF ha sido modificada en diversas ocasiones; en concreto, en el año 1997 y en el año 2007, antes de ser derogada y sustituida en el año 2010 por la actual Directiva de Servicios de comunicación audiovisual (Directiva 2010/13/UE). La reforma del 2007 y la nueva Directiva del año 2010 aportan un salto cualitativo en la concepción del sector audiovisual, al abordarlo desde la perspectiva de la distribución y difusión de contenidos y servicios audiovisuales, sin distinción entre tecnologías y soportes, en el entorno europeo. La nueva modificación propuesta en 2018 ampara los medios sociales y acota su influencia sobre los servicios de comunicación audiovisual a petición.

Palabras clave: Legislación audiovisual, televisión sin fronteras, contenidos audiovisuales.

\section{Abstract:}

Since the publication of the first European Television Without Frontiers Directive (TWF Directive), in 1989, the legislation on audiovisual content of the European Union (EU) has been marked by the emerging policy (liberalism, deregulation and re-regulation) and the market developments. Looking for the best possible legislation, not too behind or ahead of developments in the sector, the TWF Directive has been amended two times: 1997 and 2007, before being replaced by the current Audiovisual Media Services Directive ((Directive 2010/13/EU); this Directive represents a qualitative leap in the development of the audiovisual sector, taking into account the perspective of the distribution, content, and added services, regardless of the communication network used. The new modification proposed in 2018 covers social media and limits its influence on audiovisual communication services on request.

Keywords: Audiovisual legislation, television without frontiers, audiovisual contents.

\section{INTRODUCCIÓN}

La regulación europea en materia de contenidos televisivos comenzaba en el año 1989 con la aprobación de la Directiva 89/552/EEC, conocida como Televisión sin fronteras. 
La creación de esta norma suponía la asimilación del nuevo entorno global y transnacional en el que se desenvuelve un medio como la televisión a finales de los años ochenta, momento protagonizado por la aparición y extensión de las emisiones satelitales y por la emergencia de actores privados en el sector. Las fronteras se difuminaban y la política del sector público que protegía en anteriores décadas a la televisión y la política privada propia de las empresas se entrelazaban.

Por ello, cada Estado debía abandonar la soberanía sobre su sistema televisivo y adaptar la Directiva a su legislación sobre materia audiovisual en aras de unirse a la creación de un espacio audiovisual europeo común.

Desde su aprobación, dicha norma ha sido modificada en diversas ocasiones. En el presente artículo nos proponemos desgranar la evolución que ha sufrido la legislación europea sobre contenidos audiovisuales televisivos, a través de los cambios sobre la Directiva Televisión sin fronteras, que fue modificada en los años 1997 y 2007, antes de ser derogada y sustituida en el año 2010 por la actual Directiva de Servicios de comunicación audiovisual (Directiva 2010/13/UE), recientemente revisada en 2018.

\section{LA DIRECTIVA TSF ORIGINAL}

A finales de la década de los ochenta del pasado siglo, la política de la Unión Europea no debía, ni podía ser, la misma del sistema tradicional clásico de la televisión, en el que cada Estado mantenía la soberanía sobre su sistema televisivo.

Fruto de una nueva forma de entender el sector televisivo en Europa y ante la necesidad de establecer pautas básicas en el ámbito transnacional, nace la primera versión de la Directiva Televisión sin fronteras (89/552/EEC), el 3 de octubre de 1989, una norma destinada a lograr una armonización de la regulación europea en sus mínimos y apoyar la construcción paulatina de un mercado audiovisual único europeo.

Esta Directiva elevaba a rango de norma los fundamentos de la política audiovisual de la Comunidad Europea. Su principal objetivo era preservar el interés público en el entorno europeo al resguardar la diversidad cultural, la protección de los menores 
(disposiciones contra programas pornográficos o violentos), el derecho de réplica, los límites a la publicidad, las normas que atañían a los contenidos, etc.

Tabla 1. Principios Directiva 89/552/CEE "Televisión sin Fronteras".

\begin{tabular}{|c|c|}
\hline Principio general & $\begin{array}{l}\text { Los Estados miembros garantizan la libertad de recepción y no } \\
\text { obstaculizan la retransmisión en sus territorios de emisiones de } \\
\text { programas audiovisuales procedentes de otros Estados miembros, } \\
\text { aunque pueden suspender la retransmisión de programas de televisión } \\
\text { que vulneren las disposiciones de la Directiva en materia de protección } \\
\text { de menores. }\end{array}$ \\
\hline $\begin{array}{l}\text { Cuotas de } \\
\text { difusión y } \\
\text { producción }\end{array}$ & $\begin{array}{l}\text { Artículo 4: } \\
\text { Los Estados miembros deben velar, siempre que sea posible, por que los } \\
\text { organismos de radiodifusión televisiva reserven una proporción } \\
\text { mayoritaria de su tiempo de difusión a obras europeas, excluido el } \\
\text { tiempo dedicado a la información, manifestaciones deportivas, juegos, } \\
\text { publicidad, servicios de teletexto y a la televenta. } \\
\text { Artículo 5: } \\
\text { Los organismos de radiodifusión televisiva deben reservar, como } \\
\text { mínimo, el } 10 \% \text { de su tiempo de emisión o el } 10 \% \text { de su presupuesto de } \\
\text { programación a obras europeas de productores independientes. }\end{array}$ \\
\hline $\begin{array}{l}\text { Publicidad y } \\
\text { patrocinio }\end{array}$ & $\begin{array}{l}\text { Publicidad: } \\
\text { Se establece una duración máxima del } 15 \% \text { del tiempo de transmisión } \\
\text { diario, } 20 \% \text { máximo dentro de un periodo de una hora. Establece } \\
\text { también las modalidades de interrupción de los programas, } \\
\text { consideraciones éticas y prohibición o limitación de la publicidad de } \\
\text { determinados productos como tabaco, medicamentos y bebidas } \\
\text { alcohólicas. } \\
\text { Patrocinio: } \\
\text { Se permite su existencia siempre y cuando no atente contra la } \\
\text { independencia editorial, no incite a la compra de productos o servicios } \\
\text { del patrocinador ni se incluya en telediarios ni emisiones de actualidad } \\
\text { política. }\end{array}$ \\
\hline $\begin{array}{l}\text { Protección de los } \\
\text { menores }\end{array}$ & $\begin{array}{l}\text { Se prohíbe cualquier programa de carácter pornográfico o } \\
\text { extremadamente violento. Esta prohibición es extensible a todo } \\
\text { programa que pueda perjudicar a los menores, a no ser que cumpla } \\
\text { criterios de horario o esté sujeto a medidas técnicas de protección. }\end{array}$ \\
\hline $\begin{array}{l}\text { Derecho de } \\
\text { réplica }\end{array}$ & $\begin{array}{l}\text { Se reconoce el derecho de réplica cuando se lesionen los derechos } \\
\text { legítimos de una persona en un programa de televisión de cualquier } \\
\text { organismo de radiodifusión televisiva que esté bajo la jurisdicción de un } \\
\text { Estado miembro. }\end{array}$ \\
\hline
\end{tabular}

Fuente: Directiva 89/552/CEE y http://europa.eu/scadplus/leg/es/s20013.htm

RAEIC, Revista de la Asociación Española de Investigación de la Comunicación vol. 6, núm. 11 (2019), 24-45 
Sería la primera vez que en Europa se establecían los principios de una televisión sin fronteras fundamentada en la libre circulación de programas de televisión europeos en el mercado interior, además de establecer "cuotas de difusión" para las cadenas de obras europeas.

Pero la rápida evolución de la televisión en el entorno europeo, la extensión de la digitalización y el necesario ajuste de una normativa aplicable a situaciones muy diferentes en los Estados miembros hizo necesaria la modificación de la Directiva de Televisión sin Fronteras (TSF) en los últimos años de la década de los noventa del pasado siglo XX.

\section{LA REVISIÓN DE LA DIRECTIVA TELEVISIÓN SIN FRONTERAS EN 1997}

La primera reforma de la Directiva TSF fue aprobada el 30 de junio de 1997 por el Parlamento Europeo y el Consejo a través de la Directiva 97/36/EC². Esta nueva versión de la normativa reforzaba la seguridad jurídica y actualizaba los dispositivos de control de la anterior Directiva 89/552/CEE. Los principales elementos de esta revisión eran:

- Principio de jurisdicción: El Estado miembro responsable de las cadenas de televisión se determinará a partir de esta reforma de acuerdo con el lugar donde se encuentre la sede central y donde se adopten las decisiones de programación.

- Acontecimientos de gran importancia para la sociedad: La nueva versión permitía que el público pudiese acceder libremente a la retransmisión de acontecimientos considerados de gran importancia para la sociedad $y$, en particular, acontecimientos deportivos. Cada Estado miembro puede definir a partir de esta reforma una lista cerrada y modificable anualmente de acontecimientos que deben emitirse sin codificar, aunque las cadenas de pago hayan adquirido derechos exclusivos.

\footnotetext{
2 El 23 de junio de 1997, el Parlamento Europeo y el Consejo adoptaron la nueva Directiva "Televisión sin fronteras" 97/36/EC destinada a reforzar la seguridad jurídica y a modernizar el dispositivo de la Directiva 89/552/CEE.
} 
- Televenta $^{3}:$ Los programas de televenta se asimilan a la mayoría de las normas sobre publicidad televisiva: los bloques de televenta difundidos por una cadena de programación generalista tendrán una duración mínima de quince minutos sin interrupciones y deberán ser claramente identificables por medios ópticos y acústicos.

- Protección de los menores: La reforma de la Directiva de 1997 insistiría más en la protección de los menores. En particular especifica que los Estados miembros deben velar por que los programas sin codificar que puedan perjudicar el desarrollo de los menores vayan precedidos de una señal de advertencia acústica o identificados con un símbolo visual.

- Derecho de réplica: A partir de esta reforma, la emisión de la réplica deberá hacerse en condiciones tan semejantes como sea posible a las de la emisión que lesionó los legítimos derechos de cualquier persona física o jurídica.

De acuerdo con el Artículo 2 de la Directiva 97/36/EC los Estados Miembros tenían la obligación de incorporar la citada directiva a su legislación nacional antes del 30 de diciembre de 1998 y entregar a la Comisión Europea en plazos preestablecidos dos tipos de informes: uno sobre la aplicación, en general, de la Directiva (Art. 26) y, otro, sobre la aplicación particular de los artículos 4 y 5 de la Directiva (cuotas producción europea y productores independientes) ${ }^{4}$.

Además, establecía un calendario (Art. 25 bis) que indicaba que antes del 30 de junio de 2002 se llevaría a cabo una nueva revisión de la Directiva. Esta revisión, que desarrollaremos más adelante, se inició con una extensa comunicación [COM (2002) 778 final] que describía y analizaba la consecución de los principales objetivos genéricos de

\footnotetext{
${ }^{3}$ La televenta es definida en el Art. 1 de la Directiva 97/36/EC como "la radiodifusión televisiva de ofertas directas al público con miras al suministro de bienes o a la prestación de servicios, incluidos los bienes inmuebles, los derechos y las obligaciones, a cambio de una remuneración".

${ }^{4}$ La Sexta Comunicación [COM (2004)524] arrojaba un balance muy positivo/optimista de la aplicación de los art. 4 y 5 de la Directiva durante el periodo 2001-2002. El tiempo de emisión dedicado a la programación de obras europeas ascendía a un 67\% aproximadamente en el 2001 y a un 66\% en el 2002 y la programación de producciones independientes se había estabilizado en un tercio del tiempo de emisión total autorizado.
}

RAEIC, Revista de la Asociación Española de Investigación de la Comunicación vol. 6 , núm. 11 (2019), 24-45 
la Directiva, continuó con una consulta pública en el año 2003 y se plasmó en una propuesta de revisión que la Comisión Europea publicó en diciembre de 2005.

\section{PRINCIPIOS Y DIRECTRICES DE LA POLÍTICA AUDIOVISUAL DE LA UNIÓN EUROPEA ENTRE 1997/2007}

La Directiva de Televisión sin Fronteras se complementaba con principios y directrices políticas orientadas a dar cuenta de la transformación digital de las redes. Así, uno de los pilares fundamentales de la política Europea referida a la televisión y sus contenidos fue sin duda la Comunicación del año 1999 titulada: "Principios y directrices de la política comunitaria en el sector audiovisual en la era digital" (Comisión Europea, 1999). En esta comunicación, la Comisión de las Comunidades Europeas establecía las principales acciones y estrategias previstas para dar respuesta a las repercusiones futuras de las tecnologías digitales en el sector audiovisual:

La política reguladora del sector está dirigida a garantizar determinados intereses públicos, como la diversidad cultural y lingüística, la protección de los menores y la protección de los consumidores, intereses que el desarrollo tecnológico no pone en entredicho. Sin embargo, de una amplia encuesta realizada recientemente se deriva que en el futuro se necesitarán nuevos enfoques legislativos y nuevas técnicas de reglamentación. (Comisión Europea, 1999).

Para los autores de la Comunicación (1999) 657 la televisión digital, en todas sus modalidades, representaría un papel central en el audiovisual del siglo XXI, al facilitar que el ciudadano accediese a una cantidad mayor de información, contenidos audiovisuales y servicios y, además, permitir la entrada de nuevos operadores para participar en la producción y distribución de esos contenidos. Ante el desarrollo de la tecnología digital el marco jurídico de la Unión debía:

- Proteger el interés general y la libre prestación de servicios, en relación con la función social y cultural de los medios de comunicación. 
- Intentar optimizar las posibilidades de crecimiento económico y de creación de empleo en el sector audiovisual.

Todo ello implicaba insondables repercusiones sobre la política de la Unión Europea y los Estados miembros en el sector audiovisual, que planteaban nuevos problemas al marco reglamentario vigente y requerían la revisión de los procedimientos reglamentarios utilizados hasta el momento para lograr los objetivos de interés general. Para la Comisión, la cuestión no era establecer un nuevo marco reglamentario sino adaptar el existente y complementarlo:

Habida cuenta de los resultados de las consultas realizadas hasta el momento, la Comisión considera que, lejos de tener que elaborar un nuevo marco reglamentario para los contenidos audiovisuales, la Comunidad puede controlar los actuales cambios sobre la base de los instrumentos y principios existentes y, en su caso, con la promoción de iniciativas para la autorregulación. (Comisión Europea, 1999, p. 12).

Ya en el año 2001, tal y como preveía el plan de acción de la Comunicación (1999) 657 que, como comentábamos, era un texto con la finalidad expresa de la Comisión Europea de lograr una mayor flexibilidad y adaptabilidad de la regulación a la evolución tecnológica y del mercado, daba comienzo un nuevo proceso de revisión de la Directiva original que cristalizaría en el año 2007 con la Directiva Servicios de medios audiovisuales sin fronteras.

El primer paso para afrontar la revisión fue el Informe del año 2002 sobre la aplicación de la Directiva ${ }^{5}$ realizado por la Comisión. Dicho informe, en líneas generales, indicaba que la directiva TSF seguía funcionando eficazmente como garante de la libre circulación de los servicios de televisión en el ámbito de la Unión Europea, cumplía con los objetivos fundamentales de interés público que pretendía salvaguardar y, siempre según el Informe, la aplicación de los artículos cuatro y cinco, relativos al cumplimiento de los ${ }^{5} \mathrm{COM} / 2002 / 0778$ final. Cuarto informe de la Comisión al Consejo, al Parlamento europeo, al Comité Económico y Social Europeo y
al Comité de las Regiones relativo a la aplicación de la Directiva 89/552/CEE “Televisión sin fronteras". 
requisitos sobre obras europeas y producción independiente, también era bastante satisfactoria.

Pero lo más interesante de este cuarto informe sobre la aplicación de la Directiva TSF es que, según establecía el artículo 26 de la propia norma, tenía que llevar a cabo una profunda evaluación sobre los cambios de la radiodifusión televisiva en el ámbito europeo; y si este informe lo consideraba adecuado a la vista de las modificaciones producidas en los últimos años y las previsibles en un futuro cercano, tenía que presentar propuestas y un plan de trabajo concreto para adaptar la Directiva a la nueva situación.

Para ahondar en esta cuestión, la Comisión encargó a un consultor independiente, Arthur Andersen, el estudio "Previsiones de la evolución de las tecnologías y los mercados del sector audiovisual europeo hasta $2010^{\prime \prime}$. Aparte de las tendencias aportadas por el consultor, tales como el crecimiento de la oferta de plataformas multicanal, el incremento de los ingresos por abono, el mantenimiento de la cuota de audiencia en las cadenas de libre acceso, el debilitamiento económico del sector en su conjunto, o la creación y reforzamiento de grandes grupos internacionales e integrados, el estudio independiente intuía los diferentes escenarios del sector audiovisual en Europa para el año 2010:

El consultor ha señalado que la oferta de servicios audiovisuales podría evolucionar en tres posibles direcciones: la hipótesis "todo sigue igual", que sería la más probable en caso de un entorno económico negativo; una posibilidad de "interactividad", dependiendo del rápido crecimiento de nuevos servicios interactivos, y una situación de "personalización", basada en el auge de una oferta personalizada de los servicios audiovisuales existentes.[...] Las hipótesis de interactividad y de personalización tienen más probabilidades de darse en un entorno económico positivo y llevarían a una modificación sustancial de las

\footnotetext{
6 "Outlook of the development of technologies and markets for the European Audio-visual sector up to 2010". Arthur Andersen, junio 2002.
}

RAEIC, Revista de la Asociación Española de Investigación de la Comunicación vol. 6 , núm. 11 (2019), 24-45 
funciones respectivas de los agentes del mercado y de la estructura de la industria (Comisión Europea, 1999, p. 8).

Finalmente, la Comisión llegaba en noviembre de 2002 a la conclusión de que los cambios tecnológicos y del mercado llevarían a la radiodifusión televisiva en un futuro próximo a un entorno interactivo, marcado por el desarrollo de nuevas formas de consumo, por lo que era imprescindible afrontar una reforma en profundidad de la Directiva de Televisión Sin Fronteras.

La Comunicación (COM/2002/0778) incluía un programa de trabajo para la revisión de la Directiva TSF; en este programa se definían diversos temas a tratar con especial atención, se proponía una consulta pública sobre ellos a lo largo del año 2003 y se establecía un calendario de acciones futuras. Las conclusiones extraídas de dicha consulta fueron publicados por la Comisión en diciembre de 2003, en una Comunicación titulada: "El futuro de la política reguladora europea en el sector audiovisual" (Comisión Europea, 2003). Esta nueva Comunicación concluía que la situación del mercado no obligaba a una revisión inmediata de la Directiva pero sí que podría ser necesaria una reforma profunda de dicha directiva a medio plazo, por lo que proponía reflexionar seriamente sobre algunas cuestiones, bien con el asesoramiento de expertos, bien a través de estudios independientes (Comisión Europea, 2003, p. 26-27).

En consecuencia, el siguiente paso para la revisión de la Directiva TSF fue establecer diversos grupos de reflexión sobre el ámbito de aplicación de la futura norma, la regulación de la publicidad o el derecho a la información, entre otros temas. De forma paralela, se solicitaron estudios independientes sobre el impacto de las nuevas técnicas publicitarias, las medidas de fomento de contenidos europeos, la corregulación en el sector de los media y el tratamiento de la televisión interactiva en la legislación europea.

Tras analizar los resultados obtenidos por los grupos de reflexión y los informes, el 13 de diciembre de 2005, la Comisión Europea presentó al fin un borrador de su propuesta de reforma de la Directiva TSF bajo el título "Directiva de Servicios Audiovisuales", que se haría realidad en el año 2007 (GRETEL, 2006). 


\section{LA DIRECTIVA DE SERVICIOS DE MEDIOS AUDIOVISUALES SIN FRONTERAS DEL 2007: LOS CONTENIDOS SE INDEPENDIZAN DEL SOPORTE}

La versión última de la revisión de la Directiva TSF del año 1989 fue presentada en diciembre de 2007. Su nombre pasó a ser Directiva de Servicios de medios audiovisuales sin fronteras (Parlamento Europeo, 2010):

La Comisión se ha comprometido a crear un marco coherente en el mercado interior para los servicios de la sociedad de la información y los servicios de medios, modernizando el marco legal de los servicios audiovisuales, comenzando con la propuesta presentada en 2005 para modernizar la Directiva Televisión sin fronteras, convirtiéndola en una Directiva sobre los servicios de comunicación audiovisual.

Los cambios eran profundos y de calado. El objetivo primordial era actualizar la normativa existente para adaptarla a la evolución tecnológica y comercial del sector audiovisual europeo en los últimos años, estableciendo un marco regulatorio moderno, flexible y simplificado para los contenidos audiovisuales. Otros objetivos reconocidos eran aclarar las normas vigentes en materia de publicidad y hacer una distinción entre servicios que no estuviera fundada en la tecnología utilizada para su difusión. La nueva versión de la Directiva fue publicada el 18 de diciembre de 2007 y la fecha límite para su transposición a los Estados miembros quedó fijada para el 19 de diciembre de 2009.

Lo más novedoso de la nueva versión de la Directiva del 2007 consistía, evidentemente, en abarcar los contenidos audiovisuales en su conjunto con independencia del soporte o tecnología utilizada para su distribución. Este aspecto fue entendido como un paso fundamental hacia la convergencia regulatoria en materia audiovisual, aquella que no presenta distinciones basadas en el tipo de red, la tecnología, el carácter de comunicación pública o privada o el agente que provea el servicio (GRETEL, 2006). La otra gran aportación, derivada de la anterior, era la clasificación en "servicios lineales" y "servicios no lineales", según el grado de elección de la que disponga el espectador respecto al acceso a los contenidos. 
...es necesario...al menos un conjunto básico de normas coordinadas, que se apliquen a todos los servicios de comunicación audiovisual, tanto de radiodifusión televisiva (servicios de comunicación audiovisual lineales) como servicios de comunicación audiovisual a petición (servicios de comunicación audiovisual no lineales). (Parlamento Europeo, 2007)

Según la Directiva 2007/65/CE, los servicios lineales quedaban definidos como aquellos servicios tradicionales de televisión en los que la programación está sujeta a un horario definido por el proveedor de contenidos, mientras que los servicios no lineales serían aquellos en los que el espectador tiene flexibilidad total para elegir el momento de su acceso a los programas o contenidos audiovisuales, tales como televisión y noticias a la carta.

La finalidad de esta distinción es establecer un diferente nivel de regulación aplicable a cada uno de estos grupos. Los servicios lineales, es decir la radiodifusión clásica, responden a un nivel de regulación mayor, ya que eran afectos por todas las disposiciones de la Directiva Servicios de medios audiovisuales sin fronteras, incluidas las normas cuantitativas relativas a la publicidad y la obligación de dedicar, "siempre que sea posible", más de la mitad de su tiempo de emisión a obras europeas.

Por su parte, los servicios no lineales eran objeto de una regulación de mínimos y sólo le afectaban las medidas básicas relacionadas con la protección de los menores, la prohibición de la incitación al odio, la identificación del proveedor del servicio y algunas restricciones mínimas respecto a las comunicaciones comerciales, tales como la prohibición de publicidad encubierta. El objetivo de este doble rasero era impulsar la emergencia de nuevos agentes que desarrollasen diferentes servicios audiovisuales y que, en muchos casos, se encontraban todavía en fase embrionaria, con modelos de negocio incipientes y que todavía necesitarían de la máxima flexibilidad regulatoria (GRETEL, 2006, p. 57)

Otras modificaciones importantes que establecía la Directiva Servicios de medios audiovisuales sin fronteras del año 2007 se referían a la publicidad y al patrocinio. 
- Inserción de publicidad: la publicidad, salvo en el caso de películas, telefilmes, programas para niños e informativos, se liberaliza por completo, siempre y cuando se respete el límite máximo de 12 minutos de anuncios por hora. Por otro lado, se prohíbe la publicidad encubierta. ${ }^{7}$

- Product placement y menciones favorables: en principio la inserción de productos o marcas $^{8}$ sólo está prohibida en programas de información y actualidad, documentales y programas infantiles, aunque los Estados miembros podrán ser más restrictivos si así lo desean.

La norma se aplicaba a aquellas emisiones con forma y contenido similares a la televisión tradicional, estableciendo una frontera clara entre las comunicaciones públicas (radiodifusión) y las privadas, quedando estas últimas fuera de su ámbito de aplicación (GRETEL, 2006, p. 54). Por lo tanto, no quedaban regulados por esta Directiva muchos de los servicios con contenido audiovisual ofrecidos por la red Internet, tales como comunicaciones interpersonales, videoconferencias, juegos, apuestas, blogs y demás sitios creados a partir de aportaciones de los ciudadanos (Ej. el sitio YouTube / www.youtube.com) y que no tenían finalidad expresa de "comunicación de masas".

A efectos de la presente Directiva, la definición de servicios de comunicación audiovisual debe englobar únicamente servicios de comunicación audiovisual, tanto si se trata de radiodifusión televisiva como a petición, que sean medios de comunicación de masas, es decir, que estén destinados a una parte significativa del público en general y que puedan tener un claro impacto sobre él. (Parlamento Europeo, 2007).

Las principales críticas a esta nueva revisión de la Directiva se refirieron no tanto a estas cuestiones de definición como a otros aspectos centrales del texto, tales como una laxa

\footnotetext{
7 Publicidad encubierta: presentación verbal o visual de los bienes, servicios, nombre, marca o actividades de un productor de mercancías o un prestador de servicios en programas en que tal presentación tenga, de manera intencionada por parte del organismo de radiodifusión televisiva, propósito publicitario y pueda inducir al público a error en cuanto a la naturaleza de dicha presentación. Una presentación se considerará intencionada, en particular, si se hiciere a cambio de una remuneración o de un pago similar. Def. Directiva 2007/65/CE.

${ }^{8}$ Colocación de productos: toda forma de comunicación comercial audiovisual consistente en incluir o hacer referencia a un producto o servicio, o a su marca, insertándolo en un servicio de medios audiovisuales, normalmente a cambio de pago o contrapartida similar. Def. Directiva 2007/65/CE.
}

RAEIC, Revista de la Asociación Española de Investigación de la Comunicación vol. 6, núm. 11 (2019), 24-45 
regulación de la publicidad (Campos Freire, 2007) o el mantenimiento, que no endurecimiento, de la supuesta obligación de dedicar "siempre que sea posible", más de la mitad de su tiempo de emisión de los denominados servicios de comunicación audiovisual a obras europeas (Ruy Cadima, 2008).

La filosofía de la Directiva, tras su reforma en el año 2007, se verá complementada finalmente con la derogación completa del texto original en el año 2010 y su reemplazo por una Directiva completamente nueva: la Directiva de Servicios de comunicación audiovisual (Directiva 2010/13/UE) que se aprobará en marzo de 2010.

\section{LA DIRECTIVA DE SERVICIOS DE COMUNICACIÓN AUDIOVISUAL: LA CONSOLIDACIÓN DE LOS SERVICIOS DE VALOR AÑADIDO}

Como comentábamos en el párrafo anterior, la Directiva de Servicios de comunicación audiovisual (Directiva 2010/13/UE) (Parlamento Europeo, 2010), ya no modifica a la original Directiva de Televisión Sin Fronteras, sino que la sustituye definitivamente.

La actual Directiva, recoge todas las aportaciones y modificaciones de la anterior versión del 2007 y armoniza en su conjunto el texto normativo, para evitar incoherencias en su contenido, forma o expresión.

La principal definición en la Directiva es la que aparece en su Artículo 1 y que establece la consideración de "servicio de comunicación audiovisual". Este servicio es precisado en el texto como aquél proporcionado por cualquier prestador de programas audiovisuales, independientemente de si son generalistas o bajo petición, con una penetración social significativa:

un servicio [...]cuya responsabilidad editorial corresponde a un prestador del servicio de comunicación y cuya principal finalidad es proporcionar programas, con objeto de informar, entretener o educar al público en general, a través de redes de comunicaciones electrónicas [...] Este servicio de comunicación audiovisual es bien una emisión de radiodifusión televisiva [...], bien un servicio de comunicación audiovisual a petición [...]. (Parlamento Europeo, 2010). 
Además, la Directiva refleja las normas y principios aplicables a estos servicios de comunicación audiovisual y que podemos resumir en la siguiente tabla:

Tabla 2. Principios Directiva 2010/13/UE de Servicios de Comunicación Audiovisual.

\begin{tabular}{|c|c|}
\hline Principio general & $\begin{array}{l}\text { Libre prestación y circulación de servicios de comunicación audiovisual entre los } \\
\text { Estados Miembros, excepto si las emisiones difundidas incluyen programas de } \\
\text { carácter violento o pornográfico susceptibles de herir la sensibilidad de los } \\
\text { menores. También se podrán limitar la retransmisión en aquellos casos en los que } \\
\text { se estimen que entraña un peligro para el orden, la salud o la seguridad pública, } \\
\text { así como para la protección del consumidor. }\end{array}$ \\
\hline $\begin{array}{l}\text { as de } \\
\text { ión y } \\
\text { ucción }\end{array}$ & $\begin{array}{l}\text { Artículo 16: } \\
\text { Los Estados miembros velarán, siempre que sea posible y con los medios } \\
\text { adecuados, para que los organismos de radiodifusión televisiva reserven a obras } \\
\text { europeas una proporción mayoritaria de su tiempo de difusión, con exclusión del } \\
\text { tiempo dedicado a información, juegos, publicidad, servicios de teletexto y } \\
\text { televenta. } \\
\text { Artículo 17: } \\
\text { Los organismos de radiodifusión televisiva deben reservar como mínimo, siempre } \\
\text { que sea posible y con los medios adecuados, el } 10 \% \text { de su tiempo de emisión o el } \\
10 \% \text { de su presupuesto de programación a obras europeas de productores } \\
\text { independientes. }\end{array}$ \\
\hline $\begin{array}{l}\text { Publicidad, } \\
\text { patrocinio y } \\
\text { emplazamiento } \\
\text { del producto }\end{array}$ & $\begin{array}{l}\text { La proporción de anuncios de publicidad televisiva y de televenta no excederá del } \\
20 \% \text { por hora de reloj. Para este límite no se considerarán la autopromoción, el } \\
\text { patrocinio ni el product placement. Estas limitaciones no serán aplicables a los } \\
\text { canales de publicidad, televenta y autopromoción. } \\
\text { La Directiva establece también las modalidades de interrupción de los programas, } \\
\text { consideraciones éticas y prohibición o limitación de la publicidad de } \\
\text { determinados productos como tabaco, medicamentos y bebidas alcohólicas. } \\
\text { Patrocinio: } \\
\text { No debe influir en el contenido del programa, no debe incitar directamente a la } \\
\text { compra o arrendamiento de bienes o servicios concretos y deberá estar } \\
\text { claramente indicado para el espectador. } \\
\text { Emplazamiento de producto: } \\
\text { Está permitido en obras cinematográficas, películas, series, programas deportivos } \\
\text { y programas de entretenimiento; en el resto de programas (excepto programas } \\
\text { infantiles) será admisible si no se produce pago directo, es decir, si sólo se } \\
\text { produce el suministro gratuito de bienes o servicios. }\end{array}$ \\
\hline $\begin{array}{l}\text { Protección de los } \\
\text { menores }\end{array}$ & $\begin{array}{l}\text { La emisión de programas de carácter pornográfico o violento deberá venir } \\
\text { precedida por un aviso acústico o estar identificada con un símbolo visual } \\
\text { presente durante toda su emisión. }\end{array}$ \\
\hline Incitación al odio & $\begin{array}{l}\text { Los servicios de comunicación audiovisual no podrán contener ningún tipo de } \\
\text { incitación al odio por motivo de raza, sexo, religión o nacionalidad. }\end{array}$ \\
\hline Accesibilidad & $\begin{array}{l}\text { Los prestadores de servicios de comunicación audiovisual deberán mejorar la } \\
\text { accesibilidad de sus servicios para las personas con discapacidad visual o auditiva. }\end{array}$ \\
\hline $\begin{array}{l}\text { Derecho a la } \\
\text { información }\end{array}$ & $\begin{array}{l}\text { Los Estados miembros pueden garantizar que ciertos eventos considerados de } \\
\text { gran importancia para la sociedad no puedan ser retransmitidos de forma que }\end{array}$ \\
\hline
\end{tabular}

RAEIC, Revista de la Asociación Española de Investigación de la Comunicación vol. 6, núm. 11 (2019), 24-45 


\begin{tabular}{|l|l|}
\hline & $\begin{array}{l}\text { queden excluido gran parte del público del Estado /Estados miembros. Todo } \\
\text { Estado miembro podrá establecer una lista anual de tales acontecimientos. }\end{array}$ \\
\hline $\begin{array}{l}\text { Derecho de } \\
\text { réplica }\end{array}$ & $\begin{array}{l}\text { Los Estados velarán para que el ejercicio del derecho de réplica o medidas } \\
\text { equivalentes no se vea obstaculizado. La réplica se emitirá, en un plazo razonable, } \\
\text { en condiciones tan semejantes como sea posible a las de la emisión a las que se } \\
\text { refiera. }\end{array}$ \\
\hline
\end{tabular}

Fuente: Directiva 2010/13/UE

http://europa.eu/legislation summaries/audiovisual and media/am0005 es.htm

Para el seguimiento del cumplimiento y funcionamiento da la actual directiva se instituye un Comité de contacto; este comité también tendrá la función de examinar detenidamente cualquier aspecto de la evolución del sector que sea pertinente para los Estados miembros y la aplicación de la Directiva.

\section{2018: LA EMERGENCIA DE LOS MEDIOS SOCIALES}

La Directiva de Servicios de comunicación audiovisual 2010/13/UE estaba destinada, como su predecesora, a armonizar la regulación europea en sus mínimos para, según sus objetivos manifiestos, generar un mercado común de producción y distribución de programas audiovisuales en condiciones de competencia leal. Su promulgación, y consiguiente derogación de la anterior Directiva de Televisión sin fronteras, se consideró conveniente para aportar mayor racionalidad y claridad a la legislación europea existente. Pese a perder la oportunidad de incluir explícitamente a otras regulaciones, como la Convención de la Unesco de 2005 en materia de diversidad cultural (García Leiva, 2016), se observaba en los cambios en la norma un salto cualitativo, patente en la definición de servicios de comunicación audiovisual como aquellos que tienen significativa penetración social.

Pero de cara a su aplicación, los límites entre lo que debía considerarse medios con una relevante penetración no eran claros. En 2010, algunos medios no lineales (ej. vídeo bajo demanda) no parecían estar destinados a una parte reveladora del público en general, y tampoco parecía probable que pudieran tener un claro impacto en la sociedad. No obstante, la evolución en los años posteriores indica que, efectivamente, los medios no lineales que distribuyen contenidos audiovisuales han penetrado con éxito en la sociedad, y su rápido auge ha obligado a modificar la norma.

El 6 de mayo de 2015, casi un lustro después de la aprobación de la Directiva, la Comisión desarrollaba la Comunicación "Una estrategia para el Mercado Digital Europeo" 
[COM(2015)192], donde expresaba, en lo referente al medio televisivo, su preocupación ante los desequilibrios de la vigente Directiva en el entorno digital:

El ámbito de aplicación de la Directiva ya incluye tanto las emisiones de televisión tradicionales como los servicios de comunicación audiovisual a la carta, e impone una serie de normas mínimas sobre ambos tipos de servicios. En algunos aspectos, sin embargo, los servicios a la carta tienen menos obligaciones, ya que los usuarios tienen un mayor grado de elección y control sobre el contenido y el momento para verlo. (Comisión Europea, 2015).

En este contexto surge la nueva modificación de la directiva, cuyo borrador (PE-CONS 33/18) fue publicado el 12 de octubre de 2018. La actualización considera que, si bien la Directiva de Servicios de comunicación acotaba las convergencias entre la televisión e internet, nos encontramos en un entorno en el que "los nuevos prestadores, incluidos los de servicios de vídeo a petición y las plataformas de intercambio de vídeos, están ya bien asentados" y en el que "los nuevos tipos de contenidos, como los vídeos cortos o el contenido generado por los usuarios, han adquirido mayor importancia" (Comisión Europea, 2018).

Sobre estos dos ejes se configuran las principales modificaciones a la Directiva:

- Se incluyen los "servicios de medios sociales" en la aplicación de la Directiva 2010/13/UE, dado que compiten en audiencia e ingresos con los medios de comunicación social y porque deben ser objeto de protección de cara a los menores y a cualquier ciudadano frente a la incitación al odio, violencia y terrorismo. Se crea la definición de "servicio de intercambio de vídeos a través de plataforma" y de "vídeo generado por usuarios".

- Accesibilidad: la Directiva 2010/13/UE no debe crear perjuicio sobre otras normas de la Unión Europea que tengan como objetivo mejorar la accesibilidad a los servicios que dan acceso a los medios de comunicación social como páginas web o aplicaciones. 
- Protección de datos: los medios de comunicación social deben proteger especialmente los datos personales de menores.

- Obras europeas: los servicios de comunicación audiovisual a petición destinarán el $30 \%$ de sus catálogos a la promoción y distribución de obras europeas y las harán accesibles en sus plataformas. También tendrán obligaciones financieras para contribuir a la producción y formar parte de la adquisición de derechos de obras europeas.

- ERGA: desde 2014, los Estados pueden acudir al Grupo de Entidades Reguladoras Europeas para los Servicios de Comunicación Audiovisual (ERGA) para recibir asesoramiento sobre la aplicación de la directiva.

\section{CONCLUSIONES}

La proximidad de la modificación de la vigente Directiva no nos permitirá conocer cuáles serán sus efectos concluyentes hasta dentro de unos años. Pero es posible tomar las principales incertidumbres que la aplicación de la Directiva de Servicios de medios audiovisuales suscitaba y ver cómo se resuelven o complementan en el nuevo contexto de su modificación.

En el momento de la aprobación de la Directiva, las críticas más recurrentes se referían a la limitación de los servicios de comunicación audiovisual como aquellos que constituyen una actividad económica, excluyendo medios de comunicación personales; a la regulación de la publicidad y a la emisión de obras europeas.

En lo referente a la comunicación personal, como señalaba GRETEL (2006) hace ya más de una década, esta cuestión resultaba en ocasiones controvertida y parece oportuno indicar de nuevo que es imprescindible que la Directiva esté dispuesta a ser flexible y adaptable (es decir, modificable) en los próximos años en lo referente a este ámbito. La definición de los vídeos generados por usuarios supone un paso en esta dirección, pero aún la modificación establece que la Directiva no podrá ser de aplicación a entornos informativos como los vídeos que acompañan las noticias en diarios digitales, ni tampoco a otros formatos de imagen creados y distribuidos por usuarios como los GIFs. 
En cuanto a la publicidad, el establecimiento de franjas horarias en las que la publicidad no podrá exceder el $20 \%$ de cada tramo (de 6.00 a 18.00 y de 18.00 a 24.00 ) sustituye el antiguo sistema en el que el límite de difusión publicitaria se establecía por hora de emisión. La norma europea otorga en esta ocasión más flexibilidad a los Estados miembros para establecer límites con el fin de gestionar de manera más eficiente la demanda de los anunciantes y el flujo de espectadores, bajo la advertencia de la necesidad de proteger a los consumidores de una excesiva exposición a anuncios publicitarios en horarios de máxima audiencia.

Por último, en relación con la emisión de obras europeas, la Directiva de 2010 no parecía promover claramente el flujo de programas autóctonos o regionales ni imponer una visión protectora a los Estados miembros, a los que dejaba total libertad para establecer, o no, una legislación más taxativa o específica. Esta solución no parecía adecuada en un entorno presionado por los intereses del mercado en el que a los Estados miembros les resultaba difícil defender normas más restrictivas sin un apoyo supranacional. La nueva versión de la Directiva establece esta vez un porcentaje mínimo del 30\% de presencia de obras europeas, afectando esta decisión a los Servicios de comunicación audiovisual tradicionales y a petición. Esta medida se prevé que afectará, especialmente, a aquellos agentes privados que han tenido una alta penetración en los últimos años, como las plataformas de vídeo bajo demanda, que deberán ajustar sus catálogos en función de la aplicación de esta novedad en la legislación de cada país.

Como conclusión final, no dejemos de observar que el desarrollo de la norma europea en materia de contenidos audiovisuales data ya de tres décadas. Los cambios incorporados a la inicial Televisión sin fronteras denotan que se trataba de una norma primaria y poco restrictiva, pero que ha sabido adaptarse a la evolución de los medios audiovisuales y que ha dado lugar a la configuración de un entorno que con los años se ha nutrido de los efectos de la cultura global. En otras palabras, parece adecuado afirmar que tanto la Directiva Televisión sin fronteras a finales de los años ochenta como su sucesora de Servicios de comunicación audiovisual han fomentado la creación de un marco común que hoy permite que el foco no se centre en medios de difusión 
tradicionales, sino en contenidos emancipados de sus soportes y que conviven en un sistema que ya no puede comprenderse si no es a través de una mirada transnacional.

Las sucesivas modificaciones que se incorporarán a la norma deberán atender a las nuevas necesidades de los consumidores, pero lo harán sobre las bases por fin asentadas de los retos del entorno digital globalizado.

\section{REFERENCIAS BIBLIOGRÁFICAS}

Andersen, A. (2002). Outlook of the development of technologies and markets for the European Audio-visual sector up to 2010. Consultora Arthur Andersen. Recuperado de http://ec.europa.eu/avpolicy/docs/library/studies/finalised/tvoutlook/finalrep att.pdf

Campos Freire, F. (2007). La nueva directiva europea sobre medios audiovisuales remueve el mapa de la televisión. ICONO 14(9).

García Leiva, M. Trinidad. (2016). Política audiovisual europea y diversidad cultural en la era digital. Comunicación y sociedad, 27, 221-241. Recuperado en 5 de octubre de 2018, de http://www.scielo.org.mx/scielo.php?script=sci_arttext\&pid=S0188252X2016000300221\&lng=es\&tlng=es.

Grupo de Regulación de las Telecomunicaciones (GRETEL) (2005). El Sector Audiovisual y su Evolución. La Televisión. Retos y Oportunidades. Colegio Oficial Ingenieros de Telecomunicación. Recuperado de http://forohistorico.coit.es/index.php/biblioteca/libros-electronicos/item/gretel-2005el-sector-audiovisual-y-su-evolucion-la-television-retos-y-oportunidades

Ruy Cadima, F. (2008). Do audiovisual Europeu à Europa dos Cidadãos. Revista de Economía Política de las Tecnologías de la Información y Comunicación, 10(3).

Legislación y normativa europea:

PE-CONS 33/18, de 12 de octubre de 2018. Directiva del Parlamento Europeo y del Consejo por la que se modifica la Directiva 2010/13/UE sobre la coordinación de determinadas disposiciones legales, reglamentarias y administrativas de los Estados miembros relativas a la prestación de servicios de comunicación audiovisual (Directiva de servicios de comunicación audiovisual) 
COM (2015) 192 final, de 6 de mayo de 2015. Propuesta de la Comisión al Parlamento Europeo, al Consejo, al Comité Económico y Social Europeo y al Comité de las Regiones "Una Estrategia para el Mercado Único Digital de Europa"

Directiva "Servicios de comunicación audiovisual» 2010/13/UE del Parlamento Europeo y del Consejo, de 10 de marzo de 2010, sobre la coordinación de determinadas disposiciones legales, reglamentarias y administrativas de los Estados miembros relativas a la prestación de servicios de comunicación audiovisual. DO L 95 de 15.4.2010.

\section{Directiva «Servicios de medios audiovisuales sin fronteras» 2007/65/CE del}

Parlamento Europeo y del Consejo, de 11 de diciembre de 2007, por la que se modifica la Directiva 89/552/CEE del Consejo sobre la coordinación de determinadas disposiciones legales, reglamentarias y administrativas de los Estados miembros relativas al ejercicio de actividades de radiodifusión televisiva. DO L 332 de 18.12.2007. Directiva «Televisión sin fronteras» 97/36/EC destinada a reforzar la seguridad jurídica y a modernizar el dispositivo de la Directiva 89/552/CEE. DO L 202 de 30.7.1997.

Directiva «Televisión sin fronteras» 89/552/CEE del Consejo, de 3 de octubre de 1989, sobre la coordinación de determinadas disposiciones legales, reglamentarias y administrativas de los Estados Miembros relativas al ejercicio de actividades de radiodifusión televisiva. DO L 298 de 17.10.1989.

COM (2005) 646 final, de 13 de diciembre de 2005. Propuesta de Directiva del Parlamento Europeo y del Consejo por la que se modifica la Directiva 89/552/CEE del Consejo, sobre la coordinación de determinadas disposiciones legales, reglamentarias y administrativas de los Estados miembros relativas al ejercicio de actividades de radiodifusión televisiva.

COM (2004)524 final. Sexta Comunicación, de 28 de julio de 2004, relativa a la aplicación de los artículos 4 y 5 de la Directiva 89/552/CEE «Televisión sin fronteras», modificada por la Directiva 97/36/CE, en el período 2001-2002. 
COM (2003) 784 final, de 15 de diciembre 2003. Comunicación de la Comisión al Consejo, al Parlamento Europeo, al Comité Económico y Social Europeo y al Comité de las Regiones. El futuro de la política reguladora europea en el sector audiovisual.

COM (2002)778 final. Cuarto informe de la Comisión al Consejo, al Parlamento europeo, al Comité Económico y Social Europeo y al Comité de las Regiones relativo a la aplicación de la Directiva 89/552/CEE «Televisión sin fronteras»

COM (1999) 657 final. Bruselas, 14.12.1999. Principios y directrices de la política comunitaria en el sector audiovisual en la era digital. Comunicación de la Comisión al Consejo, al Parlamento europeo, al Comité Económico y social y al Comité de las regiones.

COM/97/623 final, de 2 de diciembre de 1997. Libro Verde sobre la convergencia de los sectores de telecomunicaciones, medios de comunicación y tecnologías de la información y sobre sus consecuencias para la reglamentación. 